\title{
Molecular Structure, Infrared Spectra, and Photochemistry of Isoniazid under Cryogenic Conditions
}

\author{
Ana Borba, ${ }^{\dagger}$ Andrea Gómez-Zavaglia, ${ }^{\dagger, *}$ and Rui Fausto*,† \\ Department of Chemistry, University of Coimbra, P-3004-535, Portugal, Centro de Investigación y Desarrollo \\ en Criotecnología de Alimentos, (Conicet La Plata, UNLP) RA-1900, Argentina
}

Received: April 24, 2009; Revised Manuscript Received: June 23, 2009

\begin{abstract}
In this study, the structure, spectroscopy, and photochemistry of isoniazid $\left(\mathrm{C}_{6} \mathrm{H}_{7} \mathrm{~N}_{3} \mathrm{O}, \mathrm{INH}\right)$ were studied by low-temperature infrared spectroscopy and quantum chemistry calculations. According to DFT(B3LYP)/6$311++\mathrm{G}(\mathrm{d}, \mathrm{p})$ calculations, 12 minima were found on the potential energy surface of the molecule, corresponding to two cis conformers about the $\mathrm{O}=\mathrm{C}-\mathrm{N}-\mathrm{N}$ axis $(\mathrm{C} 1, \mathrm{C} 2)$ and one form trans about this axis (T), all being 4-fold degenerate by symmetry. The $\mathrm{C} 1$ conformer was predicted to be more stable than $\mathrm{T}$ and $\mathrm{C} 2$, by 20.4 and $22.6 \mathrm{~kJ} \mathrm{~mol}^{-1}$, respectively. In consonance with these results, only $\mathrm{C} 1$ could be observed in low-temperature argon and xenon matrixes as well as in the neat glassy state prepared from the vapor of the compound at $70{ }^{\circ} \mathrm{C}$. The $\mathrm{C} 1$ conformer was also found to be the constituting monomeric unit of the crystalline phase of INH produced from warming of the low-temperature neat amorphous state. The infrared spectra of INH in the different phases studied were fully assigned. After UV $(\lambda>235 \mathrm{~nm})$ irradiation of the matrixisolated isoniazid, the compound was found to undergo photolysis through two different pathways: a Norris type I $\alpha$-cleavage leading to production of isonicotinaldehyde and $\mathrm{N}_{2} \mathrm{H}_{2}$ and a concerted sigmatropic reaction with production of pyridine, $\mathrm{CO}$ and $\mathrm{N}_{2} \mathrm{H}_{2}$. The latter reaction was found to be nearly two times faster than the former in both argon and xenon matrixes. In addition, both reactions were found to be disfavored in a xenon matrix, which is in consonance with the involvement of $\left(n, \pi^{*}\right)$ excited states in both photochemical processes.
\end{abstract}

\section{Introduction}

Isoniazid (or isonicotinic acid hydrazide, INH; see Scheme 1) has a high activity against Mycobacterium tuberculosis (the microorganism responsible for the tuberculosis disease) and is still the most widely used drug in antituberculous regimens. ${ }^{1,2}$ In particular, it has been receiving extensive use in the prevention of tuberculosis among both HIV-infected adults and children. ${ }^{3,4}$ Interestingly, INH was synthesized for the first time by Meyer and Mally in 1912, ${ }^{5}$ but its antituberculotic activity was recognized only in 1951.6

Because of its pharmacological relevance, several analytical methods have been reported for the determination of INH either in pure and dosage forms or in biological fluids. Among these analytical methods, one can mention titration, ${ }^{7-11}$ fluorometry, ${ }^{12}$ spectrophotometry, ${ }^{13-23}$ atomic absorption spectrometry, ${ }^{24}$ chemiluminescence, ${ }^{25,26}$ polarography, ${ }^{27}$ high-performance liquid chromatography, ${ }^{28-34}$ and capillary electrophoresis. ${ }^{35}$

The room temperature FTIR and Raman spectra of neat crystalline INH were reported first by Gunasekaran et al., ${ }^{36}$ which assumed the INH molecule to have $C_{s}$ symmetry. Such an assumption is, however, in contradiction with X-ray data, ${ }^{37}$ which doubtlessly proved the molecules in the crystal do not have a planar skeleton. Indeed, in the crystal, the INH molecules have the $\mathrm{O}=\mathrm{CNN}$ fragment in the cis configuration $\left(\mathrm{O}_{12}=\mathrm{C}_{11} \mathrm{~N}_{13} \mathrm{~N}_{14}\right.$ dihedral equal to $\left.4.9^{\circ}\right)$ and deviated from the plane of the aromatic ring by $19.2^{\circ}$, wehreas the amino group has one of the hydrogen atoms practically perpendicular to the

\footnotetext{
* Corresponding author. E-mail: rfausto@ci.uc.pt.

$\uparrow$ University of Coimbra.

* Centro de Investigación y Desarrollo en Criotecnología de Alimentos.
}

\section{SCHEME 1: Schematic Representation of the Molecule of INH with Adopted Atom Numbering}

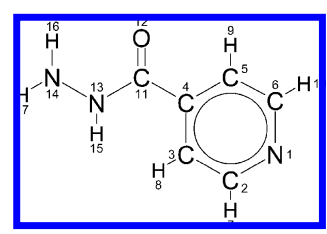

$\mathrm{O}=\mathrm{CNN}$ moiety $\left(92.1^{\circ}\right)$ and the second one making an angle of $-30.1^{\circ}$ with this fragment. ${ }^{37}$

The molecular structures of INH and of its dimers have also been investigated theoretically. ${ }^{38-40}$ With a single exception, ${ }^{38}$ all previously reported theoretical studies assumed INH to adopt the trans conformation of the $\mathrm{O}=\mathrm{CNN}$ fragment, once again in disagreement with the data obtained from X-ray diffraction. ${ }^{37}$

Regarding its reactivity, INH is known to undergo easy thermal decomposition to isonicotinic acid, isonicotinamide or $N, N^{\prime}$-bis(isonicotinic acid)hydrazide in the presence of metal ions ${ }^{41}$ hemein, ${ }^{42}$ or peroxidase ${ }^{43}$ or in alkaline solution. ${ }^{44}$ The hydrozinolysis and deamination reactions of INH were studied by Kang and co-workers, ${ }^{45}$ whereas Bhutani et al. ${ }^{46}$ reported different INH degradation reactions induced by thermal stress, hydrolysis, oxidation, and photolysis. Nicorniya and Yamamoto ${ }^{47}$ and Chiang and $\mathrm{Lin}^{48}$ showed that irradiation of INH in alcoholic solutions with UV light $(\lambda>235 \mathrm{~nm})$ produces different products, including those previously detected upon thermal decomposition of the compound plus isonicotinaldeyde isonicotinyl hydrazone and acetaldehyde isonicotinyl hydrazone. It was also shown that solid INH is not photostable, easily photodecomposing to isonicotinic acid $N^{\prime}$-(pyridine-4-carbonyl)- 


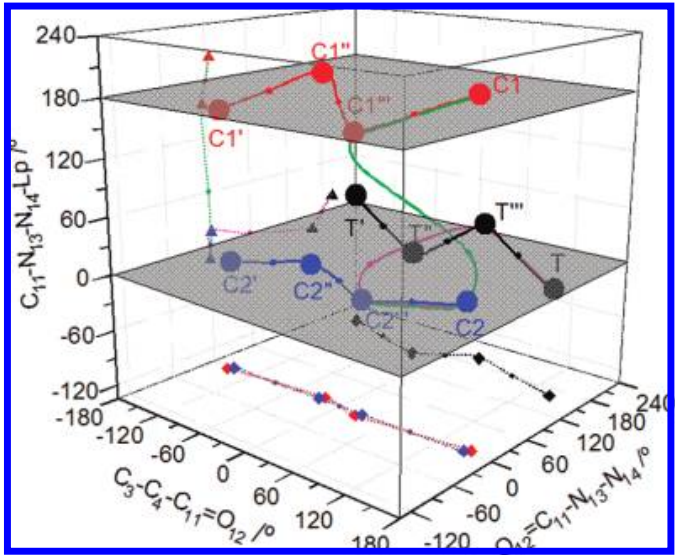

Figure 1. Schematic 3-dimensional map showing the positions of the 12 minima and transition states for conformational isomerizations in INH. The axes refer to the three conformationally relevant molecular internal rotation axes defined by the following dihedral angles: $(X)$ $\mathrm{C}_{3}-\mathrm{C}_{4}-\mathrm{C}_{11}=\mathrm{O}_{12},(Y) \mathrm{N}_{14}-\mathrm{N}_{13}-\mathrm{C}_{11}=\mathrm{O}_{12}$, and $(Z) \mathrm{C}_{11}-\mathrm{N}_{13}-\mathrm{N}_{14}-\mathrm{Lp}$ (where $\mathrm{Lp}$ corresponds to the $\mathrm{N}_{14}$ lone electron pair considered to be positioned in the bisector plane defined by the two $\mathrm{N}-\mathrm{H}$ bonds). The big spheres represent minima, whereas the small spheres represent transition states. Different colors relate to different reaction pathways, which are shown in the form of potential energy profiles in Figure 3. The represented planes parallel to the $X Y$ plane intersecting the $Z$ axis at $0^{\circ}$ and $180^{\circ}$ are shown for better perception of the position of the minima and transition states in the 3D plot. For clarity, the figure also shows the projections of the various reaction paths in the $X Y$ and $X Z$ planes. In the $X Y$ projection, the minima are represented by losangles, whereas in the $X Z$ projection, they are represented by triangles; in both projections, transition states are represented by dots.

hydrazide as the final product, by $\mathrm{SRN}_{1}$ type radical-mediated chain reaction. ${ }^{46}$

Considering the worldwide uses of INH and the interest to further understand the details of its molecular structure and reactivity, in the present study, we performed a detailed investigation of the potential energy surface of both the monomer and dimer of INH using density functional theory (DFT/B3LYP) and ab initio (Moller-Plesset to second order: MP2) levels of theory. The theoretical results were then used to help interpret the IR spectra of the compound obtained under various experimental conditions: amorphous and crystalline neat solid phases, within the $10-280 \mathrm{~K}$ temperature range and matrix-isolated INH monomer (in argon and xenon matrixes, at $10 \mathrm{~K})$. The unimolecular photodecomposition of INH was evaluated using broadband UV irradiation $(\lambda>235 \mathrm{~nm})$ of the matrix-isolated INH monomer.

\section{Experimental and Computational Methods}

INH was obtained from Aldrich (purity 99\%). The lowtemperature matrixes were prepared by codeposition of the isolating gas (argon N60 and xenon N45, both obtained from Air Liquide) and INH sublimate, in an $\sim 1000: 1$ concentration ratio, onto the cooled CsI substrate of the cryostat (APD Cryogenics close-cycle helium refrigeration system with a DE202A expander). The compound was placed in a specially designed temperature-variable mini oven assembled inside the cryostat. In all experiments, the temperature of the mini oven used to evaporate INH was $\sim 70{ }^{\circ} \mathrm{C}$. The solid film of the neat compound was prepared in a way similar to that used to obtain the matrixes, but in this case, only vapors of the compound were deposited onto the CsI substrate of the cryostat.

In the annealing experiments, the temperature was controlled and measured by a diode sensor connected to a Scientific

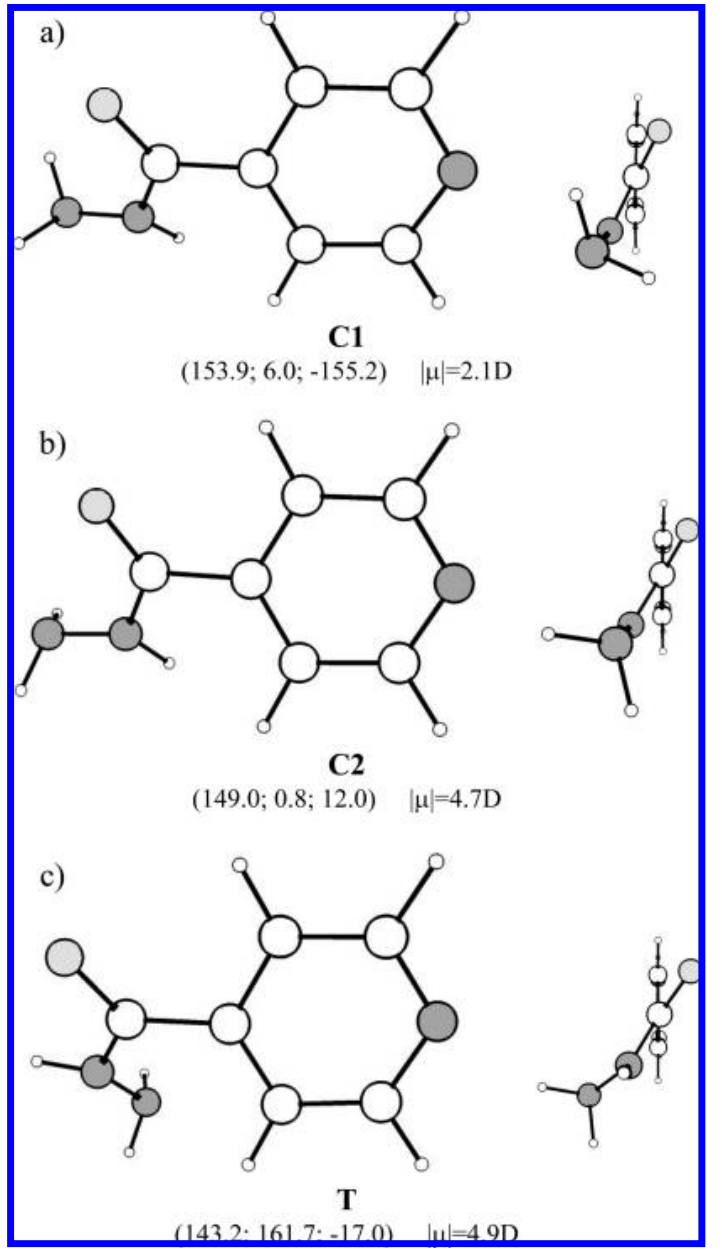

Figure 2. Optimized geometries of INH conformers at the DFT(B3LYP)/ 6-311++ $\mathrm{G}(\mathrm{d}, \mathrm{p})$ level of theory. Values in parentheses correspond to the $\mathrm{C}_{3}-\mathrm{C}_{4}-\mathrm{C}_{11}=\mathrm{O}_{12}, \mathrm{~N}_{14}-\mathrm{N}_{13}-\mathrm{C}_{11}=\mathrm{O}_{12}, \mathrm{C}_{11}-\mathrm{N}_{13}-\mathrm{N}_{14}-$ Lp dihedral angles (in degrees), where $\mathrm{Lp}$ corresponds to the $\mathrm{N}_{14}$ lone electron pair considered to be positioned in the bisector plane defined by the two $\mathrm{N}-\mathrm{H}$ bonds.

TABLE 1: Total $(E)$ and Relative $(\Delta E)$ Energies (Including Zero-Point Vibrational Contributions) for Isoniazid Conformers $^{a}$

\begin{tabular}{ccrrrr}
\hline & \multicolumn{2}{c}{ B3LYP/6-311++G(d,p) } & & \multicolumn{2}{c}{ MP2/6-31G(d,p)b } \\
\cline { 2 - 3 } \cline { 5 - 6 } conformer & \multicolumn{1}{c}{$E$} & \multicolumn{1}{c}{$\Delta E$} & & \multicolumn{1}{c}{$E$} & $\Delta E$ \\
\hline C1 & -1240055.0 & 0.0 & & -1236202.8 & 0.0 \\
T & -1240034.6 & 20.4 & & -1236183.1 & 19.8 \\
C2 & -1240032.3 & 22.7 & & -1236178.1 & 24.8
\end{tabular}

${ }^{a}$ Energies in $\mathrm{kJ} \mathrm{mol}^{-1}$; conformers are depicted in Figure 1. ${ }^{b}$ MP2 energies were corrected by zero-point energies obtained at the B3LYP/6-311++G(d,p) level of theory.

Instruments digital temperature controller (model 9659) to within $\pm 1 \mathrm{~K}$. The temperature variation during the annealing was done in steps of $2 \mathrm{~K}$ in the matrix isolation experiments and 10-20 $\mathrm{K}$ in the studies of the neat, solid compound.

The IR spectra were collected with $0.5 \mathrm{~cm}^{-1}$ spectral resolution on a Nicolet 6700 Fourier transform infrared spectrometer equipped with a deuterated triglycine sulfate detector and a Ge/KBr beamsplitter. To accommodate the cryostat head and allow efficient purging of the instrument by a stream of dry $\mathrm{N}_{2}$ to remove water and $\mathrm{CO}_{2}$ vapors, necessary modifications of the sample compartment of the spectrometer were made. 


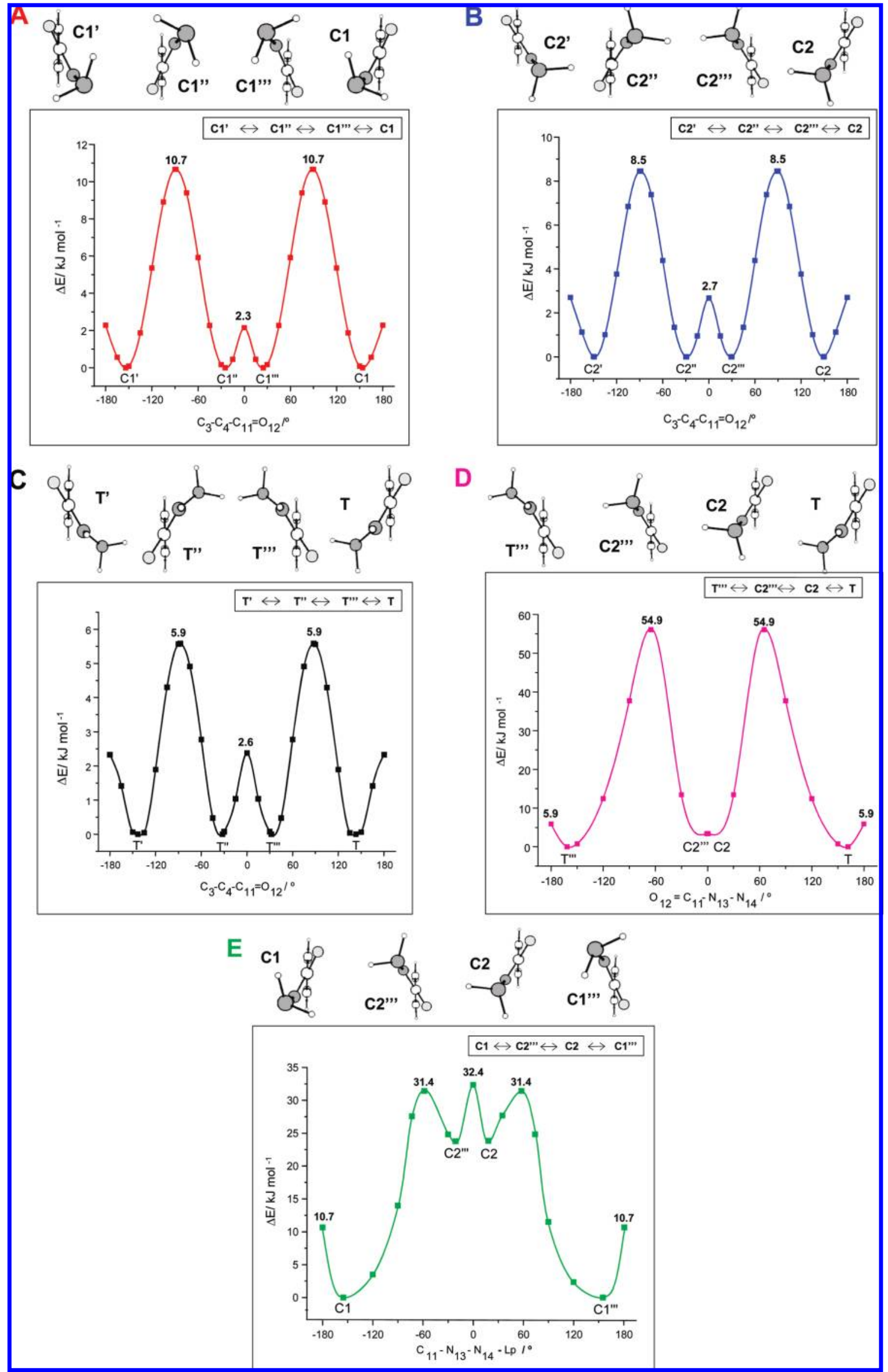

Figure 3. DFT(B3LYP)/6-311++G(d,p) calculated potential energy profiles for conformational isomerization reactions in INH. (A) $\mathrm{Cl}^{\prime} \leftrightarrow \mathrm{Cl}^{\prime \prime} \leftrightarrow \mathrm{Cl}^{\prime \prime \prime}$ $\leftrightarrow \mathrm{C} 1 ;$ (B) $\mathrm{C}^{\prime} \leftrightarrow \mathrm{C}^{\prime \prime} \leftrightarrow \mathrm{C}^{\prime \prime \prime} \leftrightarrow \mathrm{C} 2 ;(\mathrm{C}) \mathrm{T}^{\prime} \leftrightarrow \mathrm{T}^{\prime \prime} \leftrightarrow \mathrm{T}^{\prime \prime \prime} \leftrightarrow \mathrm{T},(\mathrm{D}) \mathrm{T}^{\prime \prime \prime} \leftrightarrow \mathrm{C} 2^{\prime \prime \prime} \leftrightarrow \mathrm{C} 2 \leftrightarrow \mathrm{T},(\mathrm{E}) \mathrm{C} 1 \leftrightarrow \mathrm{C} 2^{\prime \prime \prime} \leftrightarrow \mathrm{C} 2 \leftrightarrow \mathrm{C} 1^{\prime \prime \prime}$. See also Figure 1 . 


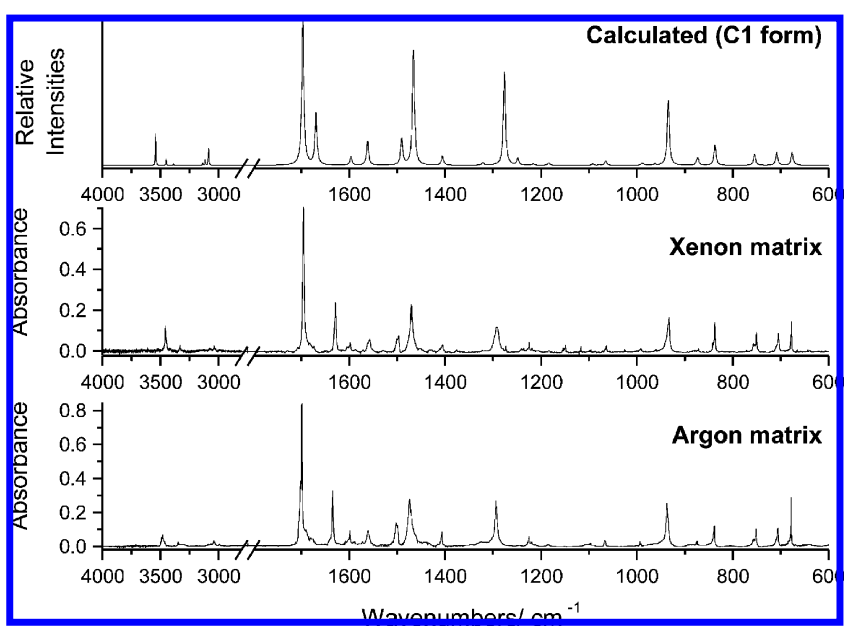

Figure 4. Infrared spectra (4000-2800 and $1800-600 \mathrm{~cm}^{-1}$ regions) of INH trapped in argon and xenon matrixes obtained immediately after deposition at 10 and $20 \mathrm{~K}$, respectively, and DFT(B3LYP)/6$311++\mathrm{G}(\mathrm{d}, \mathrm{p})$ calculated spectra for conformer $\mathrm{C} 1$. The calculated wavenumbers were scaled down by a single factor (0.978).

In situ UV $(\lambda>235 \mathrm{~nm} ; 200 \mathrm{~W})$ irradiation of the matrixes was carried out through the outer $\mathrm{KBr}$ window of the cryostat, using a $500 \mathrm{~W} \mathrm{Hg}(\mathrm{Xe})$ lamp (Newport, Oriel Instruments).

The quantum chemical calculations were performed with the Gaussian 98 suite of programs ${ }^{49}$ at the DFT and MP2 levels of theory, using the $6-311++\mathrm{G}(\mathrm{d}, \mathrm{p})$ and $6-31 \mathrm{G}(\mathrm{d}, \mathrm{p})$ basis sets, respectively. ${ }^{50}$ The DFT calculations were carried out with the three-parameter hybrid density functional abbreviated as B3LYP, which includes Becke's gradient exchange correction ${ }^{51}$ and the Lee, Yang, and Parr ${ }^{52}$ and Vosko, Wilk, and Nusair correlation functionals. ${ }^{53}$ Structures were optimized using the geometry direct inversion of the invariant subspace (GDIIS) method, ${ }^{54}$ the nature of the obtained stationary points being checked by inspection of the corresponding Hessian matrix.

The DFT(B3LYP)/6-311++G(d,p) calculated vibrational wavenumbers were scaled down by a single factor (0.978) to correct them mainly for anharmonicity effects and were used to assist the analysis of the experimental spectra. Normal coordinate analyses were undertaken in the internal coordinates space as described by Schachtschneider ${ }^{55}$ using the program BALGA and the optimized geometries and harmonic force constants resulting from the DFT calculations. Potential energy profiles for internal rotation were calculated performing a relaxed scan on the DFT(B3LYP)/6-311++G(d,p) PES along the relevant coordinates, and the transition state structures for conformational interconversion obtained using the synchronous transit-guided quasi-Newton (STQN) method. ${ }^{56}$

\section{Results and Discussion}

Geometries and Energies. INH has three internal degrees of freedom that can give rise to different conformers, which can be defined by rotations around the $\mathrm{C}_{4}-\mathrm{C}_{11}, \mathrm{C}_{11}-\mathrm{N}_{13}$, and $\mathrm{N}_{13}-\mathrm{N}_{14}$ bonds. After a full conformational search on both the DFT(B3LYP)/6-311++G(d,p) and MP2/6-31G(d,p) potential energy surfaces of the molecule, three different conformational states were found, all of them being 4 -fold

TABLE 2: Observed Wavenumbers for the Matrix Isolated INH Monomer with Band Assignments ${ }^{a, b}$

\begin{tabular}{|c|c|c|c|c|}
\hline approximate description & calculated wavenumber & calculated intensity & $\begin{array}{l}\text { observed wavenumber } \\
\text { argon matrix }(10 \mathrm{~K})\end{array}$ & $\begin{array}{l}\text { observed wavenumber } \\
\text { xenon matrix }(20 \mathrm{~K})\end{array}$ \\
\hline$v(\mathrm{~N}-\mathrm{H})$ & 3540.3 & 42.5 & $3495.5 / 3489.9 / 3481.1 / 3468.9 / 3460.8$ & $3462.4 / 3455.8 / 3449.3$ \\
\hline$v\left(\mathrm{NH}_{2}\right)$ as & 3451.1 & 8.7 & 3382.8 & 3332.1 \\
\hline$v\left(\mathrm{NH}_{2}\right) \mathrm{s}$ & 3385.7 & 2.0 & 3348.2 & 3263.6 \\
\hline$v(\mathrm{C}-\mathrm{H}) 4$ & 3134.1 & 2.4 & 3089.2 & 3178.2 \\
\hline$v(\mathrm{C}-\mathrm{H}) 3$ & 3115.0 & 7.2 & 3065.0 & 3063.1 \\
\hline$v(\mathrm{C}-\mathrm{H}) 2$ & 3088.6 & 12.8 & 3040.7 & 3035.9 \\
\hline$v(\mathrm{C}-\mathrm{H}) 1$ & 3083.0 & 19.7 & 2990.4 & 2985.0 \\
\hline$v(\mathrm{C}=\mathrm{O})$ & 1697.0 & 198.3 & $1701.7 / 1699.0$ & 1695.1 \\
\hline$\delta\left(\mathrm{NH}_{2}\right)$ & 1669.4 & 71.8 & 1635.2 & 1628.2 \\
\hline$v$ ring 5 & 1596.3 & 11.5 & 1599.6 & 1597.8 \\
\hline$v$ ring 2 & 1561.5 & 32.4 & 1561.1 & 1556.6 \\
\hline$\delta(\mathrm{C}-\mathrm{H}) 4$ & 1490.6 & 37.8 & $1502.3 / 1499.7$ & $1500.5 / 1497.2$ \\
\hline$\delta(\mathrm{N}-\mathrm{H})$ & 1466.3 & 153.2 & 1473.8 & 1470.2 \\
\hline$\delta(\mathrm{C}-\mathrm{H}) 3$ & 1405.6 & 12.3 & 1406.4 & 1404.7 \\
\hline$\delta(\mathrm{C}-\mathrm{H}) 1$ & 1321.7 & 1.5 & 13246 & $1322 ?$ \\
\hline $\mathrm{w}\left(\mathrm{NH}_{2}\right)$ & 1320.3 & 1.7 & 1324.6 & 1322.2 \\
\hline$v(\mathrm{C}-\mathrm{N})$ & 1275.6 & 126.2 & 1293.4 & 1291.7 \\
\hline$v$ ring 4 & 1248.3 & 8.6 & 1225.0 & 1273.0 \\
\hline$\delta(\mathrm{C}-\mathrm{H}) 2$ & 1216.3 & 1.9 & 1219.8 & $1224.5 / 1218.5$ \\
\hline$v(\mathrm{~N}-\mathrm{N})$ & 1184.0 & 3.5 & 1184.7 & 1182.6 \\
\hline$v$ ring 6 & 1091.6 & 1.7 & 1096.7 & 1095.9 \\
\hline$v$ ring 3 & 1078.6 & 0.8 & 1089.9 & 1087.0 \\
\hline$\delta$ ring 1 & 1064.7 & 6.0 & 1066.4 & $1066.0 / 1063.4$ \\
\hline$v$ ring 1 & 988.8 & 2.7 & 993.8 & 992.0 \\
\hline$\gamma(\mathrm{C}-\mathrm{H}) 2$ & 983.3 & 0.8 & 991.7 & 982.0 \\
\hline$\gamma(\mathrm{C}-\mathrm{H}) 3$ & 962.2 & 1.8 & 961.3 & 959.9 \\
\hline$\gamma\left(\mathrm{NH}_{2}\right)$ & 933.4 & 88.7 & 937.2 & 933.0 \\
\hline$\gamma(\mathrm{C}-\mathrm{H}) 4$ & 875.3 & 2.4 & 875.6 & 871.6 \\
\hline$\delta(\mathrm{C}=\mathrm{O})$ & 872.2 & 9.5 & 874.2 & 870.7 \\
\hline$\gamma(\mathrm{C}-\mathrm{H}) 1$ & 836.7 & 27.4 & 838.4 & $841.3 / 837.1$ \\
\hline$\gamma(\mathrm{C}=\mathrm{O})$ & 754.7 & 14.1 & $757.7 / 755.3 / 754.3 / 750.7$ & $757.0 / 754.8 / 750.4$ \\
\hline$\tau$ ring 1 & 708.2 & 17.7 & $709.5 / 705.5$ & $708.3 / 704.3$ \\
\hline $8 \operatorname{ring} 3$ & 675.9 & 172 & $678.7 / 677.4$ & $678.4 / 677.3$ \\
\hline
\end{tabular}

${ }^{a} \mathrm{~B} 3 \mathrm{LYP} / 6-311++\mathrm{G}(\mathrm{d}, \mathrm{p})$ calculated wavenumbers and intensities for conformer $\mathrm{C} 1$ are also given. ${ }^{b}$ Wavenumbers (scaled by 0.978 ) in $\mathrm{cm}^{-1}$, calculated intensities in $\mathrm{km} \mathrm{mol}{ }^{-1}$. $\nu$, bond stretching; $\delta$, bending; $\gamma$, rocking; $\tau$, torsion; w, wagging; tw, twisting; $\mathrm{s}$, symmetric; as, antisymmetric. 


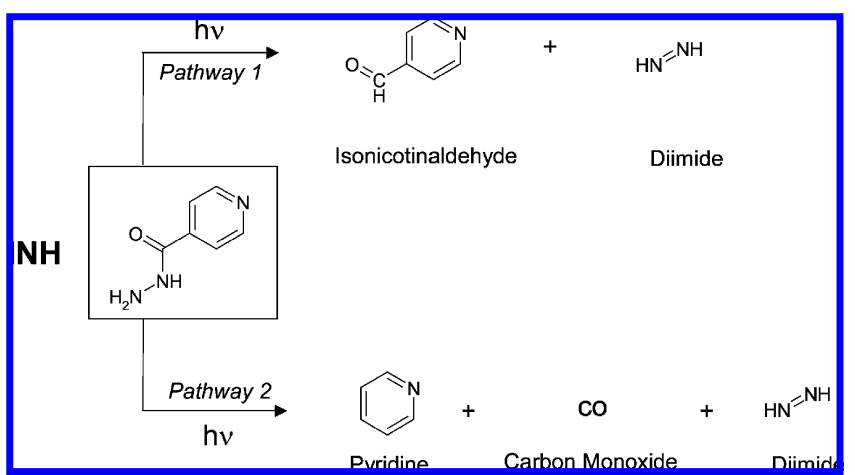

Figure 5. Proposed reaction pathways resulting from irradiation of INH monomer isolated in rare gas matrixes through the outer $\mathrm{KBr}$ window of the cryostat $(\lambda>235 \mathrm{~nm})$.

degenerate by symmetry and belonging to the $C_{1}$ symmetry point group. Figure 1 shows the position of the 12 minima in a simple 3-dimensional map whose axes refer to the three conformationally relevant molecular internal rotation axes. The structures of the $\mathrm{C} 1, \mathrm{C} 2$ and $\mathrm{T}$ conformers are shown in Figure 2. Table 1 presents their calculated relative energies, including zero-point energy corrections. The optimized geometrical parameters for the conformers are provided as electronic Supporting Information (SI), Table S1.

In consonance with the X-ray results, ${ }^{37}$ the present theoretical calculations predict conformer $\mathrm{C} 1$ as being the conformational ground state. This conformer is defined by $\mathrm{O}_{12}=\mathrm{C}_{11}-\mathrm{N}_{13}-\mathrm{N}_{14}$, $\mathrm{C}_{3}-\mathrm{C}_{4}-\mathrm{N}_{11}=\mathrm{O}_{12}, \mathrm{C}_{11}-\mathrm{N}_{13}-\mathrm{N}_{14}-\mathrm{H}_{17}$ and $\mathrm{C}_{11}-\mathrm{N}_{13}-\mathrm{N}_{14}-\mathrm{H}_{16}$ dihedral angles equal to $6.0,153.8,-82.2$, and $32.6^{\circ}$, respectively (DFT values; for MP2 values see Table S1). Among the three conformers, this form corresponds to the most planar species and is stabilized by the presence of an intramolecular hydrogen bond $\left(\mathrm{N}_{14}-\mathrm{H}_{16} \cdots \mathrm{O}_{12}\right)$. The $\mathrm{H}_{16} \cdots \mathrm{O}_{12}$ distance was predicted to be $245.9 \mathrm{pm}$, which is considerably shorter than those found, for instance, in simple amino acids such as glycine $\left(284.1 \mathrm{pm}^{57}\right)$, alanine $\left(268.7 \mathrm{pm}^{58}\right)$, and sarcosine $\left(270.1 \mathrm{pm}^{59}\right)$. This conformer is also stabilized by a weaker $\mathrm{C}_{3}-\mathrm{H}_{8} \cdots \mathrm{N}_{13}$ interaction, the $\mathrm{H}_{8} \cdots \mathrm{N}_{13}$ distance being $269.2 \mathrm{pm}$.

The second most stable conformer ( $\mathrm{T}$; see Figure 2) is characterized by $\mathrm{O}_{12}=\mathrm{C}_{11}-\mathrm{N}_{13}-\mathrm{N}_{14}, \mathrm{C}_{3}-\mathrm{C}_{4}-\mathrm{N}_{11}=\mathrm{O}_{12}, \mathrm{C}_{11}-$ $\mathrm{N}_{13}-\mathrm{N}_{14}-\mathrm{H}_{17}$, and $\mathrm{C}_{11}-\mathrm{N}_{13}-\mathrm{N}_{14}-\mathrm{H}_{16}$ dihedral angles of 163.1, $143.2,-102.1$, and $136.7^{\circ}$, respectively, and is higher in energy than $\mathrm{C} 1$ by $20.4 \mathrm{~kJ} \mathrm{~mol}^{-1}\left[19.8 \mathrm{~kJ} \mathrm{~mol}^{-1}\right.$ at the MP2/6-31G(d,p) level]. In this conformer, only a weak $\mathrm{C}_{3}-\mathrm{H}_{8} \cdots \mathrm{N}_{14}$ hydrogen bond type interaction exists, the $\mathrm{H}_{8} \cdots \mathrm{N}_{14}$ distance being 258.9 pm. In the highest energy conformer ( 22 ; see Figure 2$)$, the $\mathrm{O}_{12}=\mathrm{C}_{11}-\mathrm{N}_{13}-\mathrm{N}_{14}, \quad \mathrm{C}_{3}-\mathrm{C}_{4}-\mathrm{C}_{11}=\mathrm{O}_{12}, \quad \mathrm{C}_{11}-\mathrm{N}_{13}-\mathrm{N}_{14}-\mathrm{H}_{17}$, and $\mathrm{C}_{11}-\mathrm{N}_{13}-\mathrm{N}_{14}-\mathrm{H}_{16}$ dihedral angles are 0.7, 149.0, -130.8 , and $105.7^{\circ}$, respectively. This conformer is higher in energy than form $\mathrm{C} 1$ by $22.7 \mathrm{~kJ} \mathrm{~mol}^{-1}\left[24.8 \mathrm{~kJ} \mathrm{~mol}^{-1}\right.$ at the MP2/6$31 \mathrm{G}(\mathrm{d}, \mathrm{p})$ level] and, like conformer $\mathrm{T}$, is stabilized only by a weak $\mathrm{C}_{3}-\mathrm{H}_{8} \cdots \mathrm{N}_{13}$ interaction, the $\mathrm{H}_{8} \cdots \mathrm{N}_{13}$ distance being $271.2 \mathrm{pm}$. Because it could be expected in view of the different main stabilizing intramolecular interactions that distinguish the various conformers, the energies of the two less stable forms are similar and considerably higher than that of the most stable conformer.

Figure 3 depicts the B3LYP/6-11++G(d,p) potential energy profiles corresponding to the interconversion pathways relating the three different conformers of INH and also those between the symmetry-equivalent forms. In the case of the latter (Figure $3 \mathrm{a}-\mathrm{c}$ ), the driving coordinate is the torsion about $\mathrm{C}_{4}-\mathrm{C}_{11}$. In the calculations, the $\mathrm{C}_{3}-\mathrm{C}_{4}-\mathrm{C}_{11}=\mathrm{O}_{12}$ dihedral angle was fixed
TABLE 3: Assignment of the Bands of the Photoproducts Resulting from UV $(\lambda>235 \mathrm{~nm})$ Irradiation of INH in an Argon Matrix ${ }^{a}$

\begin{tabular}{|c|c|c|c|c|}
\hline \multirow[b]{2}{*}{$\begin{array}{l}\text { approximate } \\
\text { description }\end{array}$} & \multicolumn{2}{|l|}{ calcd } & \multicolumn{2}{|c|}{ obs } \\
\hline & wavenumbers & intensity & $\begin{array}{l}\text { sole isolated } \\
\text { species }\end{array}$ & $\begin{array}{c}\text { INH } \\
\text { photolyzed } \\
\text { Ar matrix } \\
\text { (this study) }\end{array}$ \\
\hline pyridine & & & 60,61 & \\
\hline$v$ ring 1 & 1587 & 24 & 1583 & 1593 \\
\hline$v$ ring 2 & 1582 & 10 & 1580 & 1589 \\
\hline$\delta(\mathrm{CH}) 1$ & 1477 & 2 & 1484 & 1470 \\
\hline$\delta(\mathrm{CH}) 2$ & 1437 & 27 & 1441 & 1440 \\
\hline$\delta(\mathrm{CH}) 3$ & 1214 & 5 & 1219 & n.o. \\
\hline$\delta(\mathrm{CH}) 4$ & 1144 & 2 & 1148 & 1138 \\
\hline$v(\mathrm{C}-\mathrm{N})$ asym & 1069 & 5 & 1073 & 1067 \\
\hline$\delta$ ring & 1023 & 6 & 1032 & 1032 \\
\hline$\tau$ ring 1 & 988 & 5 & 992 & 992 \\
\hline$\tau$ ring 2 & 741 & 12 & 744 & 744 \\
\hline$\gamma(\mathrm{CH})$ & 699 & 67 & 701 & 701 \\
\hline$v(\mathrm{C}-\mathrm{N})$ sym & 603 & 4 & 602 & n.o. \\
\hline carbon monoxide & & & 62 & \\
\hline$v(\mathrm{CO})$ & 2163 & 89 & 2139 & 2139 \\
\hline diimide & & & 63,64 & \\
\hline$v(\mathrm{NH})$ & 3196 & 29 & 3131 & $3320 / 3302$ \\
\hline$\delta(\mathrm{NH})$ & 1321 & 72 & 1322 & 1322 \\
\hline$\gamma(\mathrm{NH})$ & 1317 & 88 & 1286 & 1266 \\
\hline isonicotinaldehyde & & & 65 & \\
\hline$v(\mathrm{C}=\mathrm{O})$ & 1740 & 250 & 1725 & 1725 \\
\hline$v$ ring 1 & 1593 & $<1$ & 1595 & 1602 \\
\hline$v$ ring 2 & 1567 & 24 & 1570 & 1572 \\
\hline$v$ ring 3 & 1484 & 3 & 1506 & n.o. \\
\hline$v$ ring 4 & 1412 & 20 & 1414 & 1415 \\
\hline$\delta(\mathrm{CHO})$ & 1382 & 8 & 1387 & 1387 \\
\hline$\delta(\mathrm{CH}) 1$ & 1317 & 16 & 1322 & 1322 \\
\hline$v$ ring 1 & 1251 & 12 & 1226 & $1230 / 1226$ \\
\hline$\delta(\mathrm{CH}) 2$ & 1215 & 21 & 1216 & 1217 \\
\hline$v$ ring 2 & 1184 & 60 & 1200 & 1200 \\
\hline$\delta(\mathrm{CH}) 3$ & 1079 & $<1$ & 1191 & 1191 \\
\hline$\delta(\mathrm{CH}) 4$ & 1059 & 6 & 1085 & 1088 \\
\hline$\gamma(\mathrm{CHO})$ & 1007 & 2 & 1062 & $1061 / 1056 / 1046$ \\
\hline$\gamma(\mathrm{CH}) 1$ & 987 & 3 & 1004 & 1005 \\
\hline$\delta$ ring 1 & 986 & $<1$ & n.o. & 978 \\
\hline$\gamma(\mathrm{CH}) 2$ & 961 & $<1$ & 991 & 989 \\
\hline$\gamma(\mathrm{CH}) 3$ & 876 & $<1$ & n.o. & 885 \\
\hline$v(\mathrm{CC})$ & 826 & 17 & 835 & 835 \\
\hline$\gamma(\mathrm{CH}) 4$ & 802 & 42 & 801 & 802 \\
\hline$\tau$ ring & 725 & 1 & 739 & 727 \\
\hline$\delta$ ring 2 & 665 & 1 & 669 & 667 \\
\hline$\delta$ ring 3 & 644 & 38 & 647 & 647 \\
\hline
\end{tabular}

${ }^{a}$ Wavenumbers in $\mathrm{cm}^{-1}$, calculated intensities in $\mathrm{km} \mathrm{mol}^{-1} . v$, bond stretching; $\delta$, bending; $\gamma$, rocking; $\tau$, torsion; n.o., not observed; calcd, calculated; obs, observed. Calculated data were obtained at the B3LYP/6-311++G(d,p) and scaled by 0.978 .

at values differing by $15^{\circ}$, and all the other structural parameters were free to adjust to their optimal values. The minima and transition state structures were fully optimized independently as described in the Experimental and Computational Methods section. The profiles associated with the three families of conformers ( $\mathrm{C} 1, \mathrm{C} 2$, and $\mathrm{T}$ families) are similar, with two pairs of minima being separated by energy barriers lower than $3 \mathrm{~kJ}$ $\mathrm{mol}^{-1}$, which in turn are separated from each other by higher barriers $\left(\sim 6-11 \mathrm{~kJ} \mathrm{~mol}^{-1}\right)$. The first barriers are associated with transition states in which all heavy atoms are in the same plane and the weak $\mathrm{C}_{3}-\mathrm{H}_{8} \cdots \mathrm{N}_{13 / 14}$ interactions can no longer operate. On the other hand, the planarity of the molecular skeleton in these transition states favors the gain of importance of the $\mathrm{C}_{5}-\mathrm{H}_{9} \cdots \mathrm{O}_{12}$ attractive interaction. This delicate balance of stabilizing and destabilizing effects results in the observed low total energy of the transition states. In turn, the higher barriers 


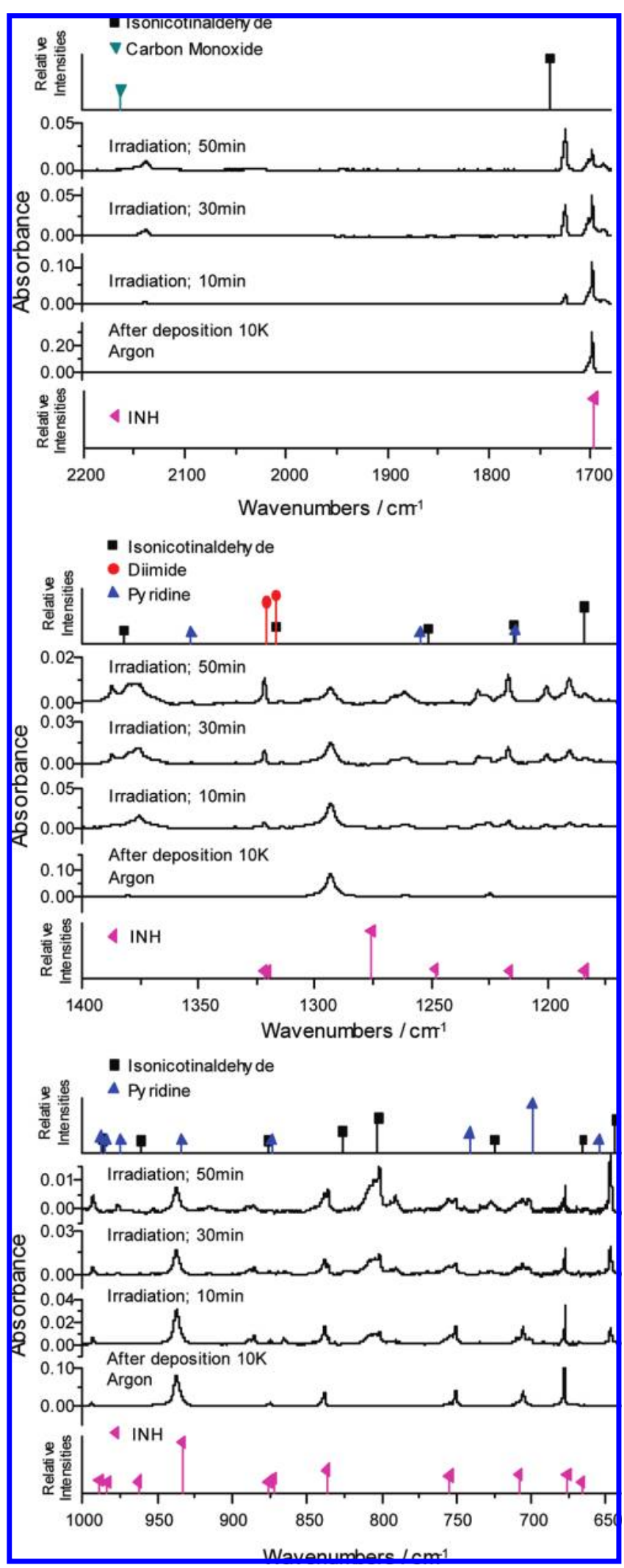

Figure 6. Infrared spectra (2200-1680, 1400-1140, and 1000-640 $\mathrm{cm}^{-1}$ regions) of the as-deposited argon matrix of INH and of the UV $(\lambda>235 \mathrm{~nm})$ irradiated matrix (after 10, 30, and $50 \mathrm{~min}$ of irradiation) and DFT(B3LYP)/6-311++G(d,p) calculated spectra for the photoproducts. The calculated wavenumbers were scaled down by a single factor (0.978).

separating the two pairs of identical conformers within each family are associated with transition states in which the
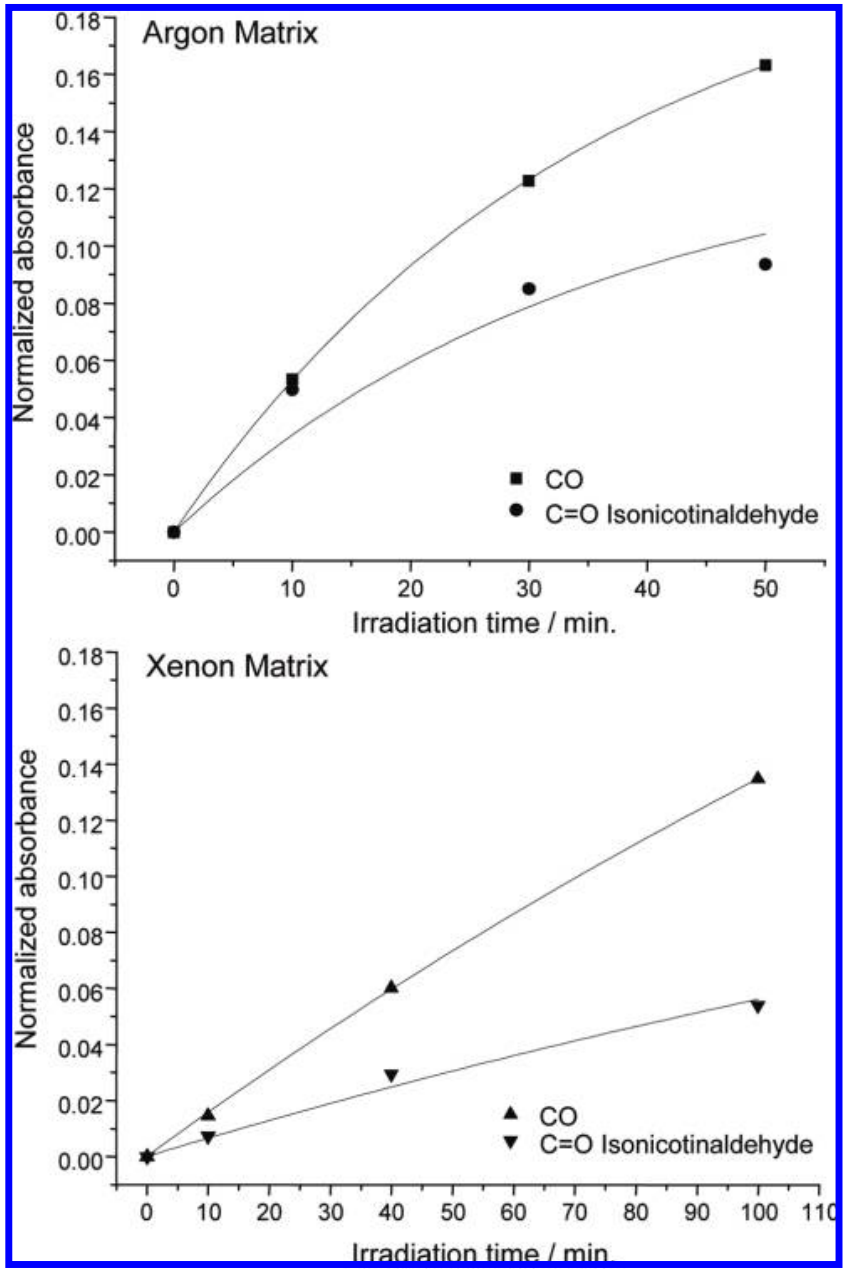

Figure 7. Plot of the normalized by calculated intensity integrated absorbances of the $v \mathrm{C}=\mathrm{O}$ stretching band of isonicotinaldehyde and $\mathrm{CO}$ band vs time of irradiation. As described in the text, these data are a measure of the extension of the photochemical pathways 1 and 2, respectively, at a given time of irradiation. The trend curves correspond to functions of the type $y=a_{\mathrm{i}} / b[1-\exp (-b t)](i=1$ for reaction 1 and $i=2$ for reaction 2 ), with parameter $b$ fitted simultaneously to the two sets of points for each matrix studied. According to the simple parallel kinetical model used, $b$ is then equal to $k_{1}+k_{2}$, where $k_{1}$ and $k_{2}$ are the rate constants for reactions 1 and 2, and the individual values for $k_{1}$ and $k_{2}$ were obtained from the following equations: $k_{\mathrm{i}}=a_{\mathrm{i}} / c$, where $c$ is a constant proportional to the initial amount of the reactant. The obtained values for $k_{1}$ and $k_{2}$ are given in the text.

$\mathrm{C}(=\mathrm{O}) \mathrm{NHNH}_{2}$ fragment is nearly perpendicular to the aromatic ring. For these geometries, additionally, no compensation occurs for the loss of the $\mathrm{C}_{3}-\mathrm{H}_{8} \cdots \mathrm{N}_{13 / 14}$ interaction and resonance stabilization involving the two fragments $\left(\mathrm{C}(=\mathrm{O}) \mathrm{NHNH}_{2}\right.$ and ring) is minimal.

Conversions between $\mathrm{C} 2$ and $\mathrm{T}$ type conformers imply essentially rotation about the $\mathrm{C}_{11}-\mathrm{N}_{13}$ bond. Hence, in the calculation of the corresponding potential energy profiles (Figure $3 \mathrm{~d}$ ), the $\mathrm{C}_{4}-\mathrm{C}_{11}-\mathrm{N}_{13}-\mathrm{N}_{14}$ dihedral angle was used as a driving coordinate. The calculated barrier for the $\mathrm{C} 2 \rightarrow \mathrm{T}$ conversion was found to be $51.5 \mathrm{~kJ} \mathrm{~mol}^{-1}\left(54.9 \mathrm{~kJ} \mathrm{~mol}^{-1}\right.$ in the inverse direction). These high energy barriers result from both disruption of the $\mathrm{C}_{3}-\mathrm{H}_{8} \cdots \mathrm{N}_{13}(\mathrm{C} 2)$ and $\mathrm{C}_{3}-\mathrm{H}_{8} \cdots \mathrm{N}_{14}(\mathrm{~T})$ and loss of resonance stabilization within the $\mathrm{C}(=\mathrm{O}) \mathrm{NHNH}_{2}$ fragment. On the other hand, in the conversion between $\mathrm{C} 2$ and $\mathrm{C} 1$ type conformers, the driving coordinate is the $\mathrm{C}_{11}-\mathrm{N}_{13}-\mathrm{N}_{14}-\mathrm{Lp}$ dihedral angle (Figure 3e). The $\mathrm{C} 2 \rightarrow \mathrm{C} 1$ energy barrier was found to be $7.5 \mathrm{~kJ} \mathrm{~mol}^{-1}\left(30.4 \mathrm{~kJ} \mathrm{~mol}^{-1}\right.$ in the inverse direction). 
SCHEME 2: Schematic Representation of the $\mathrm{H}$ Bonds in the Crystal of $\mathrm{INH}^{37}$

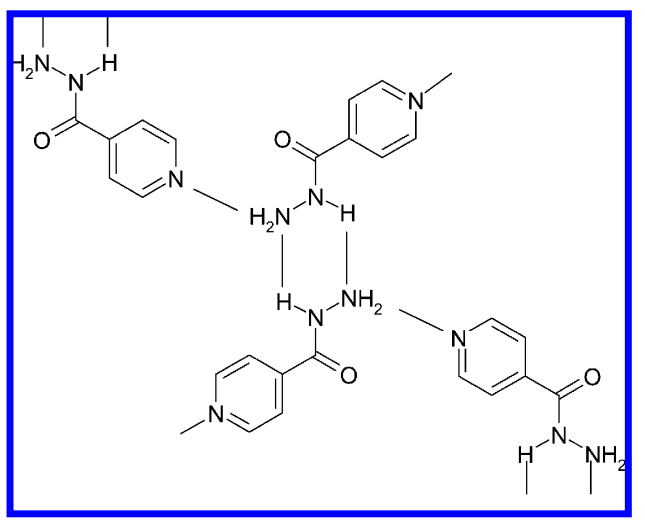

Essentially, this barrrier results from the fact that changes in the conformation about the $\mathrm{N}_{13}-\mathrm{N}_{14}$ bond drive simultaneous rotation around the $\mathrm{C}_{11}-\mathrm{N}_{13}$ bond (see Figures 1 and $3 \mathrm{e}$ ) with the consequent effects in energy terms, as described above. Finally, direct conversion between $\mathrm{T}$ and $\mathrm{C} 1$ may also occur through concerted internal rotations about the $\mathrm{C}_{11}-\mathrm{N}_{13}$ and $\mathrm{N}_{13}-\mathrm{N}_{14}$ axes, the $\mathrm{T} \rightarrow \mathrm{C} 1$ calculated energy barrier being 30.6 $\mathrm{kJ} \mathrm{mol}^{-1}\left(51.0 \mathrm{~kJ} \mathrm{~mol}^{-1}\right.$ in the reverse direction).

In summary, the potential energy surface of INH is characterized by three families of conformers: $\mathrm{C} 1, \mathrm{C} 2$, and $\mathrm{T}$. Within each family, the interconversion energy barriers are small (smaller than $\sim 11 \mathrm{~kJ} \mathrm{~mol}^{-1}$ ). Conversions between conformers belonging to different families have high energy barriers (higher than $30 \mathrm{~kJ} \mathrm{~mol}^{-1}$ ), except that between $\mathrm{C} 2$ and $\mathrm{C} 1$, which has an energy barrier of $7.5 \mathrm{~kJ} \mathrm{~mol}^{-1}$.

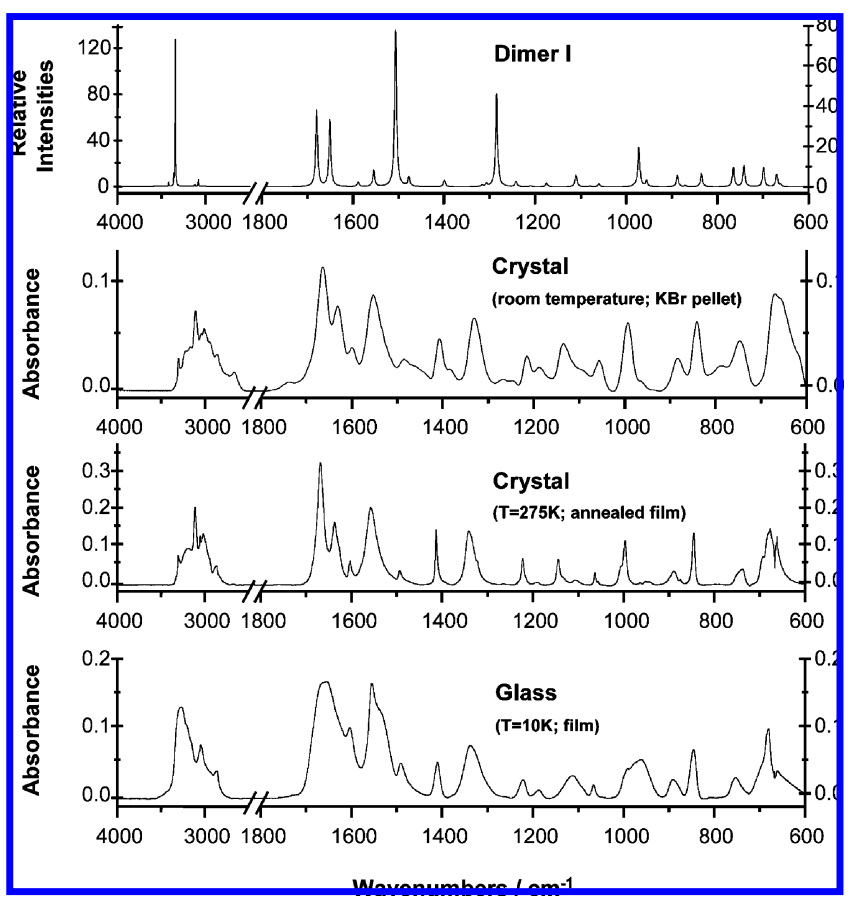

Figure 8. Infrared spectra of neat condensed phases of INH: glassy state resulting from the fast deposition of the vapor of the compound onto the cryostat's cold substrate at $10 \mathrm{~K}$ (bottom) and crystalline state resulting from annealing of the glassy film to $275 \mathrm{~K}$ (mid), room temperature crystalline phase for the compound in a $\mathrm{KBr}$ pellet (top) and DFT(B3LYP)/6-311++G(d,p) calculated spectrum for the crystallographic relevant dimer I. The calculated wavenumbers were scaled down by a single factor $(0.978)$.
Vibrational Spectra. IR Spectra of the As-Deposited Matrixes. INH has 45 fundamental vibrations, all being infraredactive. Table S2 (SI) displays the definition of the internal coordinates of INH used in the normal coordinates analysis undertaken in this study. The DFT calculated vibrational wavenumbers and infrared intensities as well as the characterization of the normal coordinates in terms of their potential energy distribution are given in Tables S3, S4, and S5 (SI) for conformers $\mathrm{C} 1, \mathrm{C} 2$, and $\mathrm{T}$, respectively. From the theoretically predicted relative energies of the INH conformers, the population of the most stable form at the temperature of sublimation of the compound in the matrix isolation experiments $\left(\sim 70{ }^{\circ} \mathrm{C}\right)$ could be estimated as being slightly larger than $99 \%$, whereas altogether, those of $\mathrm{C} 2$ and $\mathrm{T}$ forms account for less than $1 \%$ of the total population $(0.04 \%$ and $0.08 \%$, respectively). Hence, in practical terms, only $\mathrm{C} 1$ is experimentally relevant.

Figure 4 depicts the spectra of INH trapped in argon and xenon matrixes, obtained immediately after deposition, together with the calculated spectrum for conformer $\mathrm{C} 1$. Both experimental spectra nicely fit the calculated one, thus making the assignment of the bands straightforward (Table 2). In agreement with the theoretical predictions, no bands corresponding to the higher-energy forms were observed in the experimental spectra. Also in agreement with the sole presence of one conformer in the matrixes, annealing of the matrixes did not lead to any spectral changes except minor intensity variations doubtlessly ascribable to matrix site conversions.

UV-Induced Photochemistry for the Compounds in Matrixes. In situ irradiation of the matrix-isolated INH monomer allowed investigation of its unimolecular photochemistry. Upon broadband UV irradiation $(\lambda>235 \mathrm{~nm})$, the spectrum of the compound rapidly lost intensity, whereas new bands due to photoproducts developed. Figure 5 shows, in a schematic way, the reaction paths corresponding to the observed photoprocesses. The suggested band assignments for the photoproducts were based on previously reported experimental data ${ }^{60-65}$ and are provided in Table 3.

Figure 6 depicts the spectra corresponding to the argon matrixes after irradiation for different times. Irradiation of the xenon matrixes gave essentially similar results. Two of the most intense product bands are observed at $\sim 1725 \mathrm{~cm}^{-1}$, attributed to the $\nu \mathrm{C}=\mathrm{O}$ mode of isonicotinaldehyde, and at $\sim 1322 \mathrm{~cm}^{-1}$, ascribed mainly to the infrared active $\delta \mathrm{NH}$ mode of diimide, which are the products formed in pathway 1 shown in Figure 5. In addition to these two distinctive bands, the characteristic band of monomeric $\mathrm{CO}$ (found at around $2139 \mathrm{~cm}^{-1}$ in argon and at $2132 \mathrm{~cm}^{-1}$ in xenon) and the most intense band of the infrared spectrum of pyridine (at $\sim 701 \mathrm{~cm}^{-1}$ ) were also observed in the spectra of the irradiated matrixes. The fact that the bands corresponding to both $\mathrm{CO}$ and isonicotinaldehyde start growing from the very beginning of the photolysis testifies the occurrence of pathway 2 (Figure 5) and discards the possibility of $\mathrm{CO}$ being a secondary product resulting from decarbonylation of the initially formed isonicotinaldehyde. This is also in consonance with a previous study on matrix-isolated isonicotinaldehyde and its isomeric forms, nicotinaldehyde and picolinaldehyde, ${ }^{65}$ which showed that among the three studied isomeric carboxaldehydes, only picolinaldehyde decarbonylated upon UV irradiation of the matrix. In the present study, a relatively broad band at slightly higher frequency than that corresponding to the well-isolated $\mathrm{CO}$ was also observed, which is assigned to a complex formed between $\mathrm{CO}$ and pyridine. Observation of both free and associated $\mathrm{CO}$ spectral features indicates that $\mathrm{CO}$ molecules can only partially move apart from the pyridine molecule that is 
TABLE 4: Observed Frequencies for the Neat INH Solid in the Glassy State Resulting from Fast Deposition of the Vapor of the Compound onto the Cryostat's Cold Substrate at $10 \mathrm{~K}$, in the Crystalline State Resulting from Annealing of the Glassy Film $(T=275 \mathrm{~K})$, in the Room Temperature Crystalline Phase (in KBr Pellet) and Calculated Spectrum for Dimer 1C, Using the DFT(B3LYP)/6-311 $++G(d, p)$ Level of Theory ${ }^{a}$

\begin{tabular}{|c|c|c|c|c|c|}
\hline \multirow{2}{*}{$\begin{array}{l}\text { approximate } \\
\text { description }\end{array}$} & \multicolumn{2}{|c|}{ dimer $1 \mathrm{C}$} & \multirow{2}{*}{$\begin{array}{l}\text { crystal ( } \mathrm{KBr} \text { pellet, } \\
\text { room temperature) }\end{array}$} & \multirow{2}{*}{$\begin{array}{c}\text { glass } \\
\text { (film, } 10 \mathrm{~K} \text { ) }\end{array}$} & \multirow{2}{*}{$\begin{array}{c}\text { crystal } \\
\text { (film, } 275 \mathrm{~K})\end{array}$} \\
\hline & wavenumber & intensity & & & \\
\hline$v\left(\mathrm{NH}_{2}\right)$ as & 3422.2 & 25.3 & 3300.7 & & 3302.6 \\
\hline$v\left(\mathrm{NH}_{2}\right) \mathrm{s}$ & 3362.8 & 67.4 & & & \\
\hline$v(\mathrm{H}-\mathrm{N}-\mathrm{N})$ as & 3346.4 & 1001.5 & $3217.9 / 3168.3 / 3108.7 / 3044.4 /$ & $3277.5 / 3210.2 / 3065.2 / 3030.9$ & $3214.0 / 3174.8 / 3109.7 / 3050.4 /$ \\
\hline$v(\mathrm{C}-\mathrm{H})$ & 3135.2 & 5.9 & $3009.5 / 2949.7 / 2857.4$ & & $3012.0 / 2943.9$ \\
\hline$v(\mathrm{C}-\mathrm{H})$ & 3121.7 & 12.0 & & & \\
\hline$v(\mathrm{C}-\mathrm{H})$ & 3088.3 & 26.6 & 26671 & & \\
\hline$v(\mathrm{C}-\mathrm{H})$ & 3083.5 & 40.8 & 2667.1 & $2868.5 / 2857.4$ & 2865.4 \\
\hline$v(\mathrm{C}=\mathrm{O})$ & 1687.9 & 295.4 & 1663.1 & 16550 & 1667.9 \\
\hline $\mathrm{w}\left(\mathrm{NH}_{2}\right)$ & 1658.5 & 257.7 & 1631.0 & 1055.0 & 1636.5 \\
\hline$v$ ring & 1596.7 & 17.0 & 1599.6 & 1603.2 & 1602.0 \\
\hline$v$ ring & 1562.2 & 62.9 & & & 1556.8 \\
\hline $\mathrm{w}(\mathrm{H}-\mathrm{N}-\mathrm{N})$ & 1514.1 & 608.5 & 1552.8 & $1555.0 / 1533.5$ & \\
\hline$v$ ring & 1485.1 & 37.1 & 1485.4 & 1490.2 & 1493.1 \\
\hline$v$ ring & 1406.3 & 25.4 & 1407.1 & 1409.7 & 1412.7 \\
\hline$\delta(\mathrm{C}-\mathrm{H})$ & 1323.2 & 5.5 & & & \\
\hline$\delta\left(\mathrm{NH}_{2}\right)$ & 1313.9 & 10.6 & 1330.7 & 1337.4 & $1341.1 / 1322.7$ \\
\hline$v(\mathrm{C}-\mathrm{N})$ & 1291.4 & 361.2 & & & \\
\hline$v$ ring & 1248.7 & 20.6 & $1267.6 / 1246.8$ & & 1263.4 \\
\hline$\delta(\mathrm{C}-\mathrm{H})$ & 1216.5 & 3.8 & 1214.6 & 1220.7 & 1222.3 \\
\hline$\delta(\mathrm{C}-\mathrm{H})$ & 1181.2 & 14.2 & 1187.3 & 1186.6 & 1188.8 \\
\hline$v(\mathrm{H}-\mathrm{N}-\mathrm{N}) \mathrm{s}$ & 1116.6 & 46.3 & 1134.3 & 11087 & 1143.5 \\
\hline$\delta(\mathrm{C}-\mathrm{H})$ & 1085.3 & 2.8 & 1093.5 & 1108.7 & 1103.4 \\
\hline$\delta$ ring & 1065.9 & 11.5 & 1055.9 & 1065.6 & $1062.3 / 1055.6$ \\
\hline$v$ ring & 989.6 & 2.9 & & & \\
\hline$\gamma(\mathrm{C}-\mathrm{H})$ & 984.6 & 3.5 & 992.7 & $991.1 / 958.2$ & $1004.2 / 996.3$ \\
\hline$\gamma\left(\mathrm{NH}_{2}\right)$ & 977.8 & 152.6 & & & \\
\hline$\gamma(\mathrm{C}-\mathrm{H})$ & 960.9 & 23.5 & 961.4 & & 962.6 \\
\hline$\delta(\mathrm{C}=\mathrm{O})$ & 893.0 & 43.8 & & & 888.4 \\
\hline$\gamma(\mathrm{C}-\mathrm{H})$ & 876.0 & 4.1 & 882.8 & 891.3 & 874.2 \\
\hline$\gamma(\mathrm{C}-\mathrm{H})$ & 840.0 & 51.0 & 841.1 & 845.7 & 845.3 \\
\hline$\delta$ ring & 769.7 & 73.9 & 787.0 & 7519 & 7415 \\
\hline$\delta$ ring & 746.4 & 82.8 & 746.6 & 121.9 & 141.5 \\
\hline$\delta(\mathrm{C}-\mathrm{C}-\mathrm{N})$ & 703.0 & 73.3 & & & 692.4 \\
\hline$\tau$ ring & 674.0 & 49.0 & 668.6 & 680.7 & $6763 / 6613$ \\
\hline$\delta$ ring & 665.4 & 6.6 & & & $676.3 / 661.3$ \\
\hline
\end{tabular}

${ }^{a}$ The calculated spectrum was scaled down by a single factor (0.978). Frequencies in $\mathrm{cm}^{-1}$; calculated intensities in $\mathrm{km} \mathrm{mol}{ }^{-1}$. $\nu$, bond stretching; $\delta$, bending; $\gamma$, rocking; $\tau$, torsion; w, wagging; s, symmetric; as, asymmetric.

formed simultaneously upon photolysis of INH. The greater or smaller facility how the $\mathrm{CO}$ and pyridine molecules can move apart is probably dependent on the characteristics of the matrix site in which they are formed.

Because two photolysis pathways were found to be accessible, an attempt was made to estimate their relative importance. In this regard, the matrix isolation technique is especially valuable because the reactions are cage-confined, and therefore, no crossreactions take place, and one may study at leisure each pathway without any interference of the photoproducts resulting from the other one. Two bands were chosen to compare the kinetics of the two pathways: the $v \mathrm{C}=\mathrm{O}$ band of isonicotinaldehyde (formed only in pathway 1) and the band due to $\mathrm{CO}$ (produced only in pathway 2). These two bands were chosen because of two main factors: they occur in clean spectral regions, and their intensity is high enough to allow a quantitative analysis.

Figure 7 depicts the change in absorbances of the two selected bands (normalized by their calculated intensities) along irradiation time. Data corresponding to photolysis experiments carried out in both argon and xenon matrixes are shown in the figure. The first conclusion that can be extracted from the analysis of the figure is that both paths are disfavored in a xenon matrix, which is a well-known external spin-orbit coupling enhancer media. ${ }^{66}$ This result is in consonance with the involvement of $\left(n, \pi^{*}\right)$ excited states in both photochemical processes. The second conclusion is that pathway 2 was found to be the preferred one in both matrixes. Under irradiation at the conditions used in this work, the $\mathrm{CO}$ /isonicotinaldehyde ratio was found to be $\sim 2$ in argon as well as in xenon, the observed kinetics fitting well a simple parallel first-order kinetical model ${ }^{67}$ with rate constants for reactions 1 and 2 being $1.7 \pm 0.1 \times$ $10^{-2} \mathrm{~min}^{-1}$ and $1.1 \pm 0.1 \times 10^{-2} \mathrm{~min}^{-1}$ in argon and $2.4 \pm$ $0.0004 \times 10^{-3} \mathrm{~min}^{-1}$ and $1.0 \pm 0.0002 \times 10^{-3} \mathrm{~min}^{-1}$ in xenon, respectively. On the other hand, the $\mathrm{B} 3 \mathrm{LYP} / 6-311++\mathrm{G}(\mathrm{d}, \mathrm{p})$ calculated reaction energies were 137.8 and $140.8 \mathrm{~kJ} \mathrm{~mol}^{-1}$, for pathways 1 and 2, respectively; that is, nearly equal.

Taking into account all observations described above, it can be concluded that pathway 1 corresponds to a characteristic ( $n$, $\left.\pi^{*}\right)$ Norris type I $\alpha$-cleavage of the $\mathrm{C}_{11}-\mathrm{N}_{13}$ bond, leading to the primary production of the $\mathrm{NC}_{5} \mathrm{H}_{4} \mathrm{C}=\mathrm{O}$ and $\mathrm{H}_{2} \mathrm{NNH}$ radicals, which since being matrix-cage-confined can easily rearrange to the final products by $\mathrm{H}$-atom transfer. On the other hand, pathway 2 occurs, with all probability, through a concerted mechanism, with a lower energy barrier. Very interestingly, such a concerted mechanism can be expected to be favored by a translike structure about the $\mathrm{C}_{11}-\mathrm{N}_{13}$ bond, pointing to the relevance of a structure similar to conformer $\mathrm{T}$ in the involved excited state(s). This hypothesis, however, must be confirmed through 


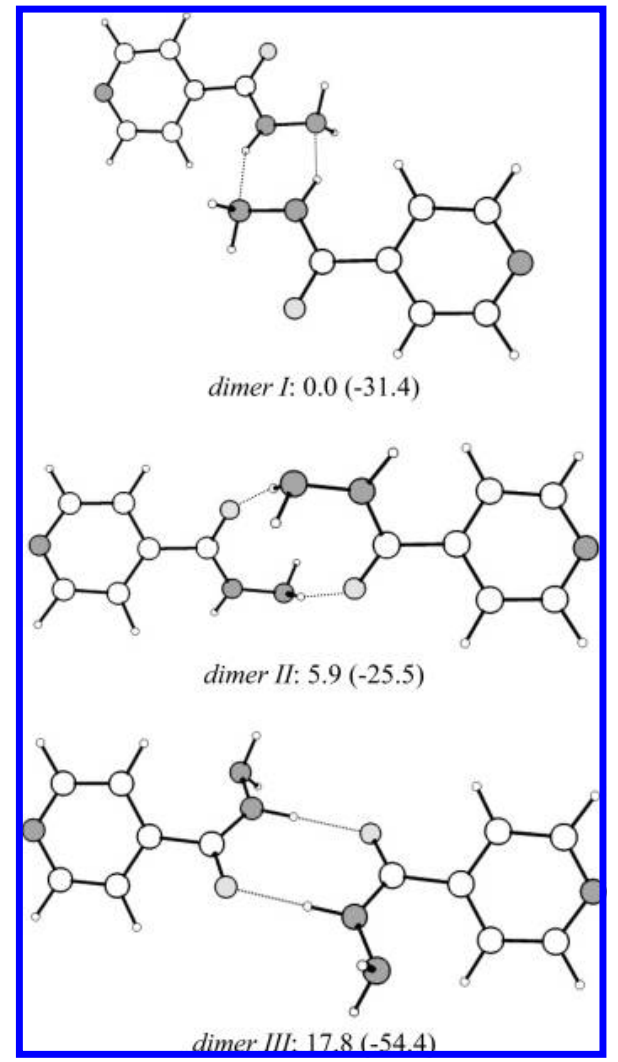

Figure 9. DFT(B3LYP)/6-311++G(d,p) calculated structures for the most stable dimers of INH based on the most stable $\mathrm{C} 1$ monomeric structure (dimers I and III) and on the T conformer (dimer II). Dimer I corresponds to the crystallographic relevant dimeric structure (see Scheme 2) ${ }^{37}$ Relative energies of the dimers and dimerization energies [calculated as $E$ (dimer) $-2 \times E$ (monomer); in parentheses] are given in $\mathrm{kJ} \mathrm{mol}^{-1}$. All the dimers belonging to the $C_{i}$ symmetry point group.

high-level computational studies on the excited state potential energy surfaces of INH.

Neat Solid State Vibrational Spectra. The structure of the INH crystal at room temperature was obtained by X-ray diffraction long ago. ${ }^{37}$ The number of molecules in the unit cell (orthorhombic, $a_{\mathrm{o}}=11.33 \AA ; b_{\mathrm{o}}=14.74 \AA$; $c_{\mathrm{o}}=3.84 \AA$; space group $P 2{ }_{1} 2_{1} 2_{1}$ ) was found to be 4 , all of them assuming the $\mathrm{C} 1$ conformation. In the crystal, there are two types of intermolecular $-\mathrm{N}-\mathrm{H} \cdot \cdots \mathrm{N}-$ bonds: the strongest type connects the amide hydrogen atom of one molecule (I in Scheme 2) to the amine nitrogen of a second molecule (II) and vice versa, forming a dimer; the second and weaker type connects one of the amine hydrogen atoms of each constituent of the dimer unit to the endocyclic nitrogen atom of another molecule (III and IV). In view of the importance of the dimeric unit in the INH crystal, in the present study, we have optimized its structure and calculated its infrared spectra, which was used in the analysis of the spectra obtained experimentally for the solid neat compound.

Figure 8 displays the IR spectra of INH in the neat lowtemperature amorphous phase resulting from fast deposition of the vapor of the compound onto the cold $(10 \mathrm{~K})$ substrate of the cryostat as well as in the crystalline state resulting from warming that sample up to $275 \mathrm{~K}$. The spectrum of the room temperature polycrystalline phase of INH in $\mathrm{KBr}$ pellet, as well as the calculated spectrum for the crystallographically relevant dimer unit, are also presented in this figure, for comparison (the predicted spectra for other low-energy dimeric structures are provided in the Supporting Information, Figure S1). The pro- posed assignments are given in Table 4. As could be expected considering the essentially unordered arrangement of the INH molecules in the amorphous phase, the spectrum of this phase is constituted by rather broad bands, which become progressively narrower upon warming due to relaxation to more ordered states. Upon crystallization of the sample (at $270 \mathrm{~K}$ ), the infrared spectrum becomes essentially equal to that of an INH polycrystalline sample in $\mathrm{KBr}$ pellet at room temperature. This observation proves that the two crystals are identical.

Since we were interested in understanding in more detail the aggregation preferences of INH, in addition to the crystallographic relevant dimer, we looked for other low-energy dimeric structures. Not surprisingly, the crystallographic relevant dimer (dimer I) resulted in the ground state structure of the isolated INH dimer. Its calculated dimerization energy, as given by the difference between the energy of the dimer and the sum of its constituting monomeric units, amounts to $-31.4 \mathrm{~kJ} \mathrm{~mol}^{-1}$. Very interestingly, among all the dimers investigated, the centrosymmetric dimer based on conformer $\mathrm{T}$ bearing a typical amide dimer hydrogen bond linkage (dimer III in Figure 9) was found to be the one having the most favorable dimerization energy, $-54.4 \mathrm{~kJ} \mathrm{~mol}^{-1}$, almost twice that found for the experimentally relevant and most stable dimer I. This indicates that the intermolecular H-bonds are considerably stronger in dimer III than in dimer I. Nevertheless, although the dimerization energy of dimer III is quite favorable, its energy is still considerably higher than that of dimer I $\left(17.8 \mathrm{~kJ} \mathrm{~mol}^{-1}\right)$ because of the much higher intrinsic energy of their constituting monomeric units ( $\mathrm{T}$ conformer). Note also that both $\mathrm{C} 1$ and $\mathrm{C} 2$ conformers can also form dimers with a pair of $\mathrm{NH}_{\text {(amide) }} \cdots \mathrm{O}$ intermolecular hydrogen bonds, but in these two cases, this $\mathrm{H}$ bond motiff leads to formation of an energetically disfavored 11-membered ring instead of the very stable typical 8-membered ring amide dimer resulting when the constituting monomers adopt the $\mathrm{T}$ conformation (see Figure 9).

\section{Conclusion}

Quantum chemistry calculations on INH molecule revealed the existence of 12 minimum energy conformations, corresponding to three 4-fold degenerate by symmetry conformational states. Two of these different conformational states possess a cis arrangement about the $\mathrm{O}=\mathrm{C}-\mathrm{N}-\mathrm{N}$ axis $(\mathrm{C} 1, \mathrm{C} 2)$, whereas the remaining one is trans about this axis $(\mathrm{T})$. The $\mathrm{C} 1$ conformer was predicted to be more stable than $\mathrm{T}$ and $\mathrm{C} 2$, by 20.4 and $22.6 \mathrm{~kJ} \mathrm{~mol}^{-1}$, respectively, and was the sole conformer experimentally observed for the matrix-isolated compound as well as in the neat, low-temperature, glassy state prepared from deposition of the vapor of the compound at $70{ }^{\circ} \mathrm{C}$ onto a substrate cooled to $10 \mathrm{~K}$. The $\mathrm{C} 1$ conformer was also found to be the constituting monomeric unit of the crystalline phase of INH produced from warming of the low-temperature, neat, amorphous state.

The relative stability of the three conformers was interpreted in terms of intramolecular interactions, the considerably greater stability of the $\mathrm{C} 1$ form being ascribed to the presence in this form of a relatively strong $\mathrm{H}$ bond $\left(\mathrm{N}_{14}-\mathrm{H}_{16} \cdots \mathrm{O}_{12}\right)$. Reaction pathways for conformational isomerization were obtained. It was shown that interconversion energy barriers are small within a given family of conformers (smaller than $\sim 11 \mathrm{~kJ} \mathrm{~mol}^{-1}$ ), whereas conversions between conformers belonging to different families have high energy barriers (higher than $30 \mathrm{~kJ} \mathrm{~mol}^{-1}$ ) except that between $\mathrm{C} 2$ and $\mathrm{C} 1$, which has an energy barrier of $7.5 \mathrm{~kJ} \mathrm{~mol}^{-1}$.

The infrared spectra of INH in the different phases studied were fully assigned. 
After UV $(\lambda>235 \mathrm{~nm})$ irradiation of the matrix-isolated isoniazid, the compound was found to undergo photolysis through two different pathways: a slower Norris type I $\alpha$-cleavage, leading to production of isonicotinaldehyde and $\mathrm{N}_{2} \mathrm{H}_{2}$, and a faster concerted sigmatropic reaction with production of pyridine, $\mathrm{CO}$, and $\mathrm{N}_{2} \mathrm{H}_{2}$. The latter reaction was found to be nearly 2 times faster than the first one in both argon and xenon matrixes. In addition, both reactions were found to be disfavored in a xenon matrix, which is in consonance with the involvement of $\left(n, \pi^{*}\right)$ excited states in both photochemical processes.

Acknowledgment. This work was supported by FCT (Project PTDC/QUI/71203/2006), CYTED (108RT0362), and ANPCyT (Project PICT/2006/0068). A.B. acknowledges FCT for the award of a Ph.D. grant (SFRH/BD/21543/2005). A.G.Z. is member of the Research Career of CONICET (National Research Council, Argentina).

Supporting Information Available: Figure S1, with DFT(B3LYP)/6-311++G(d,p) calculated infrared spectra (4000-2800 and $1800-0 \mathrm{~cm}^{-1}$ regions) of INH dimers. Table S1 with optimized structural parameters and experimental geometries; Table S2 with definition of internal coordinates used in the normal coordinate calculations; Tables S3-S5 with calculated IR spectra and results of the normal coordinate analysis for the three conformers of isoniazid. This information is available free of charge via the Internet at http://pubs.acs.org.

\section{References and Notes}

(1) Klopman, G.; Fercu, D.; Jacob, J. Computer-Aided Study of the Relationship between Structure and Antituberculosis Activity of a Series of Isoniazid Derivatives. Chem. Phvs. 1996, 204 (2-3), 181-193.

(2) Silva, F. P.; Ellena, J.; Ferreira, M. D.; Mascarenhas, Y. P.; de Souza, M. V. N.; Vasconcelos, T. R. A.; Wardell, J. L.; Wardell, S. Experimental and Theoretical Structure Characterization of Two Isoniazid Derivatives: 2,4-Difluoro- $N^{\prime}$-isonicotinoylbenzohydrazide and 2,4-Dichloro$N^{\prime}$-isonicotinoylbenzohydrazide Hydrochloride. $\underline{\text { J. Mol. Struct. }}$ 2006, 788 (1-3), 63-71.

(3) Szakacs, T. A.; Wilson, D.; Cameron, D. W.; Clark, M.; Kocheleff, P.; Muller, F. J.; McCarthy, A. E. Adherence with Isoniazid for Prevention of Tuberculosis among HIV-Infected Adults in South Africa. Bmc Infect. Dis. 2006, 6, 97-103.

(4) Gray, D. M.; Zar, H.; Cotton, M. Impact of Tuberculosis Preventive Therapy on Tuberculosis and Mortality in HIV-Infected Children. Cochrane Database Syst. Rev. 2009, 115.

(5) Meyer, H.; Mally, J. Monatsh. Chem. 1912, 33, 393.

(6) Domagk, G.; Offe, H. A.; Siefken, W. Ein weiterer beitrag zur experimentellen chemotherapie der tuberkulose (neoteben). Dtsch. Med. Wochenschr. 1952, 77 (2), 573-578.

(7) British Pharmacopoeia; HM Stationary Office: London 1988;p 957.

(8) The United States Pharmacopeia XXII - National Formulary XVII; US Pharmacopeial Convention: Rockvilla, 1990.

(9) British Pharmacopoeia, Majesty's Stationary Office: London, 1993.

(10) Khalifa, H.; Abdelghani, N. T.; Issa, Y. M.; Ibrahim, H. Potentiometric Determination of Titanium(Iii), Tin(Ii), and Some Hydrazine Derivatives. Microchem. J. 1988, 38 (2), 206-210.

(11) El-Brashy, A. M.; El-Ashry, S. M. Colorimetric and Titrimetric Assay of Isoniazid. J. Pharm. Biomed. Anal. 1992, 10 (6), 421-426.

(12) Ioannou, P. C. A Simple and Rapid Fluorimetric Method for the Microdetermination of Isonicotinic Acid Hydrazide. Talanta 1987, 34 (10), $857-860$.

(13) Sastry, C. S. P.; Rao, S. G.; Naidu, P. Y.; Srinivas, K. R. Rapid, Routine Method for the Analysis of Some Drugs with Bromate and Celestine Blue. Anal. Lett. 1998, 31 (2), 263-273.

(14) El-Brashy, A. M.; El-Hussein, L. A. Colorimetric Determination of Some Important Hydrazine Derivatives. Anal. Lett. 1997, 30 (3), 609 622 .

(15) Nagaraja, P.; Srinivasa Murthy, K. C.; Yathirajan, H. S. Spectrophotometric Determination of Isoniazid with Sodium 1,2-Naphthoquinone4-sulphonate and Cetyltrimethyl Ammonium Bromide. Talanta 1996, 43 (7), 1075-1080.

(16) Mahfouz, N. M. A.; Emara, K. M. Colorimetric Determination of Isoniazid and Its Pharmaceutical Formulations. Talanta 1993, 40 (7), 10231029 .
(17) El-Brashy, A. M.; Ibrahim, F. A.; El-Ashry, S. M. Colorimetric Determination of Some Important Hydrazine Derivatives. Microchim. Acta 1991, 105 (4), 105-110.

(18) Ibrahim, F. A.; Rizk, M. S.; Belal, F. Tetracyanoethylene in Pharmaceutical Analysis 0.1. A Spectrophotometric Method for the Determination of Some Pharmaceutically Important Hydrazine and Pyrazolone Derivatives. Analvst 1986, 111 (11), 1285-1287.

(19) Ibrahim, F.; Belal, F.; Hassan, S. M.; Aly, F. A. Spectrophotometric Determination of Some MAO Inhibitors Using 7,7,8,8-Tetracyanoquinodimethane and Iodine Monochloride. J. Pharm. Biomed. Anal. 1991, 9 (2), 101-107.

(20) Kaveeshwar, R.; Gupta, V. K. A New Spectrophotometric Method for the Determination of Hydrazine in Environmental-Samples. Fresenius' J. Anal. Chem. 1992, 344 (3), 114-117.

(21) Yatsimirsky, A. K.; Yatsimirskaya, N. T.; Kashina, S. B. Micellar Catalysis and Product Stabilization in Hydrazone Formation Reactions and Micellar-Modified Determination of Hydrazine and Phenylhydrazine. Anal. Chem. 1994, 66 (14), 2232-2239.

(22) Manes, J.; Campillos, P.; Font, G.; Martre, H.; Prognon, P. Extraction-Spectrophotometric Determination of Hydrazine with 2-Hydroxy-1-naphthaldehyde. Analvst 1987, 112 (8), 1183-1184.

(23) Zamora, L. L.; Mateo, J. V. G.; Calatayud, J. M. Entrapment of Reagents in Polymeric Materials - Indirect Atomic-Absorption Spectrometric Determination of Isoniazid by Oxidation with Manganese-Dioxide Incorporated in Polyester Resin Beads in a Flow-Injection System. Anal. Chim. Acta 1992, 265 (1), 81-86.

(24) Song, Z.; Lü, J.; Zhao, T. Chemiluminescence Sensor for Isoniazid with Controlled-Reagent-Release Technology. Talanta 2001, 53 (6), 11711177.

(25) Zheng, X. W.; Zhang, Z. J. Flow-Injection Chemiluminescence Determination of Isoniazid Using on-Line Electrogenerated $\mathrm{BrO}^{-}$as Oxidant. Analvst 1999, 124 (5), 763-766.

(26) Hou, W.; Ji, H.; Wang, E. Amperometric Flow-Injection Analysis of Hydrazine by Electrocatalytic Oxidation at Cobalt Tetraphenylporphyrin Modified Electrode with Heat Treatment. Talanta 1992, 39 (1), 45-50.

(27) Belal, F.; Ibrahim, F. A.; Hassan, S. M.; Aly, F. A. Polarographic and Spectrophotometric Determination of Isocarboxazid and Tranylcypromine Sulphate through Treatment with Nitrous Acid. Microchim. Acta 1991, 105 (1), 61-69.

(28) Sadeg, N.; Pertat, N.; Dutertre, H.; Dumontet, M. Rapid, Specific and Sensitive Method for Isoniazid Determination in Serum. J. Chromatogr... B 1996, 675 (1), 113-117.

(29) Argekar, A. P.; Kunjir, S. S. Simultaneous Determination of Isoniazid and Pyridoxine Hydrochloride in Pharmaceutical Preparations by High-Performance Thin-Layer Chromatography. J. Planar Chromatogr.Mod. TLC 1996, 9 (5), 390-394.

(30) Defilippi, A.; Piancone, G.; Laia, R. C.; Tibaldi, G. P. An HPLC Screening Method for the Detection of Isonicotinic Acid Hydrazide in Cattle Milk. Chromatographia 1995, 40 (3-4), 170-174.

(31) Zhou, J.; Wang, E. Electrocatalysis and Determination of Hydrazine Compounds in Liquid Chromatography at a Mixed-Valent Cobalt Oxide/ Cyanocobaltate Film Electrode. Talanta 1993, 40 (6), 943-948.

(32) Kirchherr, H. Determination of Hydrazine in Human Plasma by High-Performance Liquid-Chromatography. J. Chromatogr., Biomed. Appl. 1993, 617 (1), 157-162.

(33) Vatsala, S.; Bansal, V.; Tuli, D. K.; Rai, M. M.; Jain, S. K.; Srivastava, S. P.; Bhatnagar, A. K. Gas-Chromatographic Determination of Residual Hydrazine and Morpholine in Boiler Feed Water and Steam Condensates. Chromatographia 1994, 38 (7-8), 456-460.

(34) Preece, N. E.; Forrow, S.; Ghatineh, S.; Langley, G. J.; Timbrell, J. A. Determination of Hydrazine in Biofluids by Capillary Gas-Chromatography with Nitrogen-Sensitive or Mass-Spectrometric Detection. J. Chromatogr., Biomed. Appl. 1992, 573 (2), 227-234.

(35) Liu, J.; Zhou, W. H.; You, T. Y.; Li, F. L.; Wang, E. K.; Dong, S. J. Detection of Hydrazine, Methylhydrazine, and Isoniazid by Capillary Electrophoresis with a Palladium Modified Microdisk Array Electrode. Anal. Chem. 1996, 68 (19), 3350-3353.

(36) Gunasekaran, S.; Kumar, R. T.; Ponnusamy, S.; Pushparaj, S. E. Vibrational Spectra and Normal Coordinate Analysis of Isoniazid. Indian J. Phvs. Proc. Indian Assoc. Cultivation Sci. 2005, 79 (2), 171-175.

(37) Jensen, L. H. The Crystal Structure of Isonicotinic Acid Hydrazide. J. Am. Chem. Soc. 1954, 76 (18), 4663-4667.

(38) Akalin, E.; Akyuz, S. Vibrational Structure of Free and Hydrogen Bonded Complexes of Isoniazid: FT-IR, FT-Raman and DFT Study. J. Mol. Struct. 2007, 834, 492-497.

(39) Yilmaz, A.; Bolukbasi, C.; Bakiler, M. An Experimental and Theoretical Vibrational Spectra of Isomazide. J. Mol. Struct. 2008, 872 (23), 182-189.

(40) Favila, A.; Gallo, M.; Glossman-Mitnik, D. CHIH-DFT Determination of the Molecular Structure Infrared Spectra, UV Spectra and Chemical Reactivity of Three Antitubercular Compounds: Rifampicin, Isoniazid and Pyrazinamide. J. Mol. Model. 2007, 13 (4), 505-518. 
(41) Winder, F. G.; Denneny, J. M. Metal-Catalysed Auto-Oxidation of Isoniazid. Biochem. J. 1959, 73, 500-507.

(42) Albert, A.; Rees, C. W. Destruction of Isonicotinic Acid Hydrazide in the Presence of Haemin. Biochem. J. 1955, 61 (1), 128-131.

(43) Loth, H.; Hengstma, Kd. Enzymatic Oxidation of Aromatic Acyl Hydrazides. Arch. Pharm. 1971, 304 (9), 696.

(44) Kakemi, K.; Sezaki, H.; Nadai, T.; Nishikio, K.; Inoue, S.; Ono, Y. Stability of Isoniazid and Its Related Compounds 0.7. Stability of Isonicotinic Acid Hydrazide Sodium Methanesulfonate. Yakugaku Zasshi 1971, 91 (1), 95.

(45) Kang, S. K.; Lee, J. H.; Lee, Y. C.; Kim, C. H. Catalase-Peroxidase of Mycobacterium bovis BCG Converts Isoniazid to Isonicotinamide, but Not to Isonicotinic Acid: Differentiation Parameter between Enzymes of Mycobacterium bovis BCG and Mycobacterium tuberculosis. Biochim. Biophvs. Acta 2006, 1760 (5), 724-729.

(46) Bhutani, H.; Singh, S.; Vir, S.; Bhutani, K. K.; Kumar, R.; Chakraborti, A. K.; Jindal, K. C. LC and LC-MS Study of Stress Decomposition Behaviour of Isoniazid and Establishment of Validated Stability-Indicating Assay Method. J. Pharm. Biomed. Anal. 2007, 43 (4), $1213-1220$

(47) Ninomiya, I.; Yamamoto, O. Photochemistry of Isonicotinohydrazide and Its Analogs in Alcohol. Heterocvcles 1976, 4 (3), 475-481.

(48) Chiang, H. C.; Lin, L. J. Photolysis of Isoniazid. J. Chin. Chem. Soc. 1978, 25 (3), 125-130.

(49) Frisch, M. J. T.; Trucks, G. W.; Schlegel, H. B.; Scuseria, G. E.; Robb, M. A.; Cheeseman, J. R.; Zakrzewski, V. G.; Montgomery, J. A.; Stratmann, R. E.; Burant, J. C.; Dapprich, S.; Millam, J. M.; Daniels, A. D.; Kudin, K. N.; Strain, M. C.; Farkas, O.; Tomasi, J.; Barone, V.; Cossi, M.; Cammi, M.; Mennucci, B.; Pomelli, C.; Adamo, C.; Clifford, S.; Ochterski, J.; Petersson, G. A.; Ayala, P. Y.; Cui, Q.; Morokuma, K.; Malick, D. K.; Rabuck, A. D.; Raghavachari, K.; Foresman, J. B.; Cioslowski, J.; Ortiz, J. V.; Baboul, A. G.; Stefanov, B. B.; Liu, G.; Liashenko, A.; Piskorz, P.; Komaromi, I.; Gomperts, R.; Martin, R. L.; Fox, D. J.; Keith, T.; Al-Laham, M. A.; Peng, C. Y.; Nanayakkara, A.; Challacombe, M.; Gill, P. M.; Johnson, B. G.; Chen, W.; Wong, M. W.; Andres, J. L.; Gonzalez, C.; HeadGordon, M.; Replogle, E. S.; Pople, J. A. Gaussian 98, Revision A. 09, Gaussian, Inc.: Pittsburgh, PA, 1998.

(50) Frisch, M. J.; Head-Gordon, M.; Pople, J. A. Semidirect Algorithms for the MP2 Energy and Gradient. Chem. Phvs. Lett. 1990, 166 (3), 281289.

(51) Becke, A. D. Density-Functional Exchange-Energy Approximation with Correct Asymptotic-Behavior. Phys. Rev. A 1988, 38 (6), 3098-3100.

(52) Lee, C. T.; Yang, W. T.; Parr, R. G. Development of the ColleSalvetti Correlation-Energy Formula into a Functional of the ElectronDensity. Phvs. Rev. B 1988, 37 (2), 785-789.
(53) Vosko, S. H.; Wilk, L.; Nusair, M. Accurate Spin-Dependent Electron Liquid Correlation Energies for Local Spin-Density Calculationsa Critical Analysis. Can. J. Phys. 1980, 58 (8), 1200-1211.

(54) Csaszar, P.; Pulay, P. Geometry Optimization by Direct Inversion in the Iterative Subspace. J. Mol. Struct. 1984, 114, 31-34.

(55) Schachtschneider, J. H.; Mortimer, F. S. Vibrational Analysis of Polyatomic Molecules. VI. FORTRAN IV Programs for Solving the Vibrational Secular Equation and for the Least-Squares Refinement of Force Constants, Project No. 31450. Structural Interpretation of Spectra; Shell Development Co: Houston, TX, 1965.

(56) Peng, C.; Schlegel, H. Combining Synchronous Transit and QuasiNewton Methods to Find Transition-States. Isr. J. Chem. 1994, 33, 449.

(57) Stepanian, S. G.; Reva, I. D.; Radchenko, E. D.; Rosado, M. T. S.;

Duarte, M.; Fausto, R.; Adamowicz, L. Matrix-Isolation Infrared and Theoretical Studies of the Glycine Conformers. J. Phys. Chem. A 1998, 102 (6), 1041-1054.

(58) Rosado, M. T. S.; Duarte, M.; Fausto, R. Vibrational Spectra (FTIR, Raman and MI-IR) of $\alpha$ - and $\beta$-Alanine. J. Mol. Struct. 1997, 410, 343-348.

(59) Gomez-Zavaglia, A.; Fausto, R. Conformational Study of Sarcosine As Probed by Matrix-Isolation FT-IR Spectroscopy and Molecular Orbital Calculations. Vibr. Spectrosc. 2003, 33 (1-2), 105-126.

(60) Kudoh, S.; Takayanagi, M.; Nakata, M. Dewar Pyridine Studied by Matrix Isolation Infrared Spectroscopy and DFT Calculation. $\underline{J}$. Photochem. Photobiol. Chem., A 1999, 123 (1-3), 25-30.

(61) Johnstone, D. E.; Sodeau, J. R. Matrix-Controlled Photochemistry of Benzene and Pyridine. J. Phvs. Chem. 1991, 95 (1), 165-169.

(62) Maki, A. G. Infrared Spectra of Carbon Monoxide As a Solid and in Solid Matrices. J. Chem. Phvs. 1961, 35 (3), 931-935.

(63) Bondybey, V. E.; Nibler, J. W. Infrared and Raman-Spectra of Solid and Matrix-Isolated Diimide, HNNH. J. Chem. Phvs. 1973, 58 (5), 21252134

(64) Craig, N. C.; Levin, I. W. Vibrational Assignment and Potential Function for trans-Diazene (Diimide) - Predictions for cis-Diazene. J. Chem. Phys. 1979, 71 (1), 400-407.

(65) Ohno, K.; Itoh, T.; Yokota, C.; Katsumoto, Y. Matrix-Isolation Infrared Spectra of 2-, 3- and 4-Pyridinecarboxaldehyde before and after UV Irradiation. J. Mol. Struct. 2006, $825(1-3), 143-150$.

(66) Turro, N. J. Modern Photochemistry; Benjamin/Cummings: Menlo Park, NJ, 1978; Chapter 5.

(67) Capellos, C.; Bielski, H. J. B. Kinetic Systems: Mathematical Description of Chemical Kinetics in Solution; Wiley-Interscience: New York, 1972; Chapter 11.

JP9037914 